\title{
Introduction: Organizing hope: Narratives for a better future
}

\section{Daniel Ericsson and Monika Kostera}

According to thinkers such as Zygmunt Bauman (2017a) and Wolfgang Streeck (2016), the current social world is ruled by a crumbling, morbid system. Old social institutions are failing and no new ones have yet emerged. This state in between ruling institutions has been labeled the interregnum by Bauman (2012), using Antonio Gramsci's metaphor. "The crisis consists precisely in the fact that the old is dying and the new cannot be born; in this interregnum a great variety of morbid symptoms appear" (Gramsci, 1971, p. 276), Gramsci foretold. Rather than literally denoting an era after the death of one sovereign yet before the enthronement of a new monarch, in today's late global capitalism an interregnum denotes "times of uncertainty, and while [it is] raising many questions, three of them seem particularly pertinent to address at a time when rulers no longer can rule and the ruled no longer wish to be ruled: institutional disparity, the future of migrants and the endurability of the planet" (Bauman, 2012, p. 51).

The structures that once supported collective social action (Bauman, 2012) and which enabled more or less smooth self-regulation of economic mechanisms (Streeck, 2016) have lost their taken-for-granted character and often reveal their powerlessness to solve any of the mounting problems that face humanity and the planet. The usual resourcefulness and responsibility that seemed to be found at the bottom of modernity are giving way to direct violence and what looks like a relentless raid on the common good, blatant malice, greed, mounting fear, uncertainty and a sense of powerlessness. Humanity seems to have betrayed its values or, with the rapid dismantling and discarding of the institutions that once held memory and social identity, such as academia and eldership, it may even look as if it never really had them, as if it all were a dream or a lie.

Humans however depend on making sense of the world and life, perhaps as much as on nourishing their bodies for survival and so on. In times of rabid meaninglessness, we fill the unbearable void with whatever we are able to find, such as simplified and idolized images of "what it used to be 
like," a phantasmatic past that has never been. Modern countries, organizations and ideologies in this sense seem to go backward in time, engaging in a nostalgic yet politically consequential quest for a "retrotopia," in Zygmunt Bauman's word (2017a).

Without any structures linking us to utopias located in the future, humanity thus seems to have run out of faith. Instead, we have made a full U-turn and pursue pasts that would redeem us from the present and all the problems it presents. But it is not possible to turn back the clock and, even less, recreate a past that has never been. In the words of Zygmunt Bauman:

There are no shortcuts leading to a quick, adroit and effortless damming of the "back to" currents - whether to Hobbes, to tribes, to inequality or to the womb. ... We need to brace ourselves for a long period marked by more questions than answers and more problems than solutions, as well as for acting in the shadow of finely balanced chances of success and defeat. But in this one case - in opposition to the cases to which Margaret Thatcher used to impute it - the verdict "there is no alternative" will hold fast, with no likelihood of appeal. More than at any other time, we - human inhabitants of the Earth - are in the either/or situation: we face joining either hands, or common graves. (Bauman, 2017a, pp. 166-167)

In this book, we have gathered a collection of chapters that provide different answers to Bauman's call, considering what can be done to alter the direction of the dead course on which humanity seems to be set. The authors we invited to partake in our endeavor were encouraged to come up with ideas that would make it worthwhile for humanity to take itself through the abyss to the other side of the interregnum and dare to try to build a new system, hopefully better and more just for everyone and kinder to the planet we share, because, like Bauman, we believe that much now depends on our ability and courage to collectively rethink the state of the world and find hope - a gift and an ability that has nothing to do with optimism but much with the power of social imagination (Bauman, 2016).

In our call for contributions, we stressed the importance of organizing hope, partly because we consider the joining of hands in order to move beyond the interregnum to be essentially a matter of coordinating people, resources, energies, inspirations and aspirations, and partly because we believe that the social imagination of hope is especially crucial on the organizational level. Coupled with critical awareness and an active use of courageous thinking, it is in our organizations that new ideas will be formed (or old ones re-formed) to cope with our present-day dilemmas and problems. This is an activity at the heart of what organization theorist Heather Höpfl (2013) used to regard as the necessary, redeeming resistance 
against a morbid system, and for a desired future after the current system is abolished. As such, it brings hope in a situation defined by its hopelessness.

Our project unfolds in relation to a large and growing number of publications depicting the bleak state of the world and trying to draw attention to the shocking seriousness of our current situation. Concerned voices are raised from different perspectives and places in the political spectrum, from socialist sociologist Zygmunt Bauman (2017a), to environmental activist Naomi Klein (2014), to deep ecology author Clive Ponting (2007), to conservative philosopher Rafał Matyja (2018). Organization and management theory has its own abundant literature of this kind, including in recent years: Cederström and Fleming (2012), Alvesson (2014), Skoglund (2015) and Fleming (2017). These are very important and much needed, as is the growing interest in alternative organizations (for example Parker et al., 2007; Parker, 2011; Kostera, 2014; Reedy et al., 2016).

Few engaged social scientists and readers of social science need convincing that things are not as good as they were promising to be for many just a few decades ago, as David Graeber (2015) compellingly demonstrates. We do not think it is good or promising. Instead, we very much agree with Peter Fleming's (2019) diagnosis: the worst is yet to come. Overpowered by suicidal work ethics, planetary destruction, financial crashes and treacherous and completely irresponsible politicians we are, in fact, all together in the sinking ship of capitalism. A few billionaires are getting more outrageously rich every day, at the expense of all the rest of us. But there is much more to come, and there are no reasons to be cheerful. There are specters haunting the sociosphere: of all the good futures that never happened, the dreams we had, but also of the grisly future that has not yet materialized.

To face all this, we need a special mindset Fleming (2019) proposes, and he lists four possible responses. The first is optimism, and it suggests that things are improving - in fact, are quite good already - and makes use of different measures, mostly statistical, to make buoyant points. It may result in colorful and funny moving graphs, but the audience is increasingly hard to convince. The second is nihilism, which recommends embracing the destruction and bleakness to make a buck on it, or two. Misery can be profitable for those who know how to profit from it. Apart from being sadistic at best and psychopathic at worst, it is also extremely stupid. Not even the most expensive hideaway on New Zealand will save the rich from planetary destruction when the day comes.

The third response is radical positivity, preached by some energetic activists from the left. In the face of disaster, we should do whatever is within our power to resist it and save ourselves and the planet from the wreckage. As true as this message is, it is also, unfortunately, not encouraging: not 
much is within our power. The fourth and last proposition is Fleming's own, which he calls revolutionary pessimism. It is a response which "does [not] succumb to resignation, even in the face of insurmountable odds," but "anticipates the nastiest surprises that a derailed civilization has to offer, yet refuses the cult of futility" (2019, p. 39).

Revolutionary pessimism however is quite an Anglo-Saxon response. Being Swedish and Polish, we do not completely resonate with this mindset, even though we recognize both its beauty and its use. Instead, we propose a fifth response with Slavic-Scandi undertones: radical mourning together with persistent hope. Historically Slavs have not been the happiest of people, most of them (except Russians) constantly being attacked and occupied by not too friendly invaders from all sides. They have therefore developed a great talent for mourning and obstinacy, which is equaled by the Scandinavian stubbornness in the face of unforgiving natural conditions, poverty and darkness. Swedes know that the past is not going to come back, and, even if it did, this is no reason to celebrate. Poles (and Czechs) know that hope is nothing like fluffy optimism but can take the inelegant form of pigheaded refusal to accept that the dominant order is obvious or normal or, indeed, one with legitimacy to define the future. Vaclav Havel, who knew rather well what he was speaking of, said the following in Disturbing the Peace:

Hope, in this deep and powerful sense, is not the same as joy that things are going well, or willingness to invest in enterprises that are obviously headed for early success, but rather an ability to work for something because it is good, not just because it stands a chance to succeed. The more unpromising the situation in which we demonstrate hope, the deeper that hope is. Hope is not the same thing as optimism. It is not the conviction that something will turn out well, but the certainty that something makes sense, regardless of how it turns out. In short, I think that the deepest and most important form of hope, the only one that can keep us above water and urge us to good works, and the only true source of the breathtaking dimension of the human spirit and its efforts, is something we get, as it were, from "elsewhere." It is also this hope, above all, that gives us the strength to live and continually to try new things, even in conditions that seem as hopeless as ours do, here and now. (Havel, 1990, p. 182)

Zygmunt Bauman (2017b), the Polish sociologist, held a similar view on the matter, explaining that, for a social scientist, hope is the desire and also the impulse to make our planet a more hospitable place to live. It is a radical act, because it is immortal, has its roots in the future, and needs no proof rooted in the past. It makes life worth living. Such hope needs no justification, no motivation and no cheerful state of mind - it is the desire to live, the lust of life even under the most dispiriting circumstances. In 
short, it is a refusal to make things easy for them, whoever they are, and give up and die.

Poles and Swedes in this vein simply don't give up, and this is not because they constantly feel like dancing. The Polish peasant Ślimak, for example, protagonist of the novel The Outpost by Bolesław Prus (1953), knows very well that the occupying Prussian empire is overpowering and that nobody will come to save him and his family. He is called Ślimak, the Snail, not because he is "stupid," but because he is slow to change his mind and sympathies. Ślimak thus refuses to sell his farm to German settlers, even though that would have profited him, because he does not want to change his identity and become a laborer. The farm stands out as an impossible outpost of Polishness and autonomy but is in the end saved by Ślimak with help from his poor Jewish friend Jojne.

Equally persistent are Swedish farmers Karl Oskar Nilsson and his wife Kristina, protagonists of the novel The Emigrants by Vilhelm Moberg (2013). Karl Oskar and Kristina are struggling to keep their farm in an almost barren land and unforgiving climate. Their hard work, loyalty and dedication, however, do not bring them a happy ending. When their son dies, they decide to emigrate to the USA, escaping poverty but never giving up on who they are and what they care about.

Radical mourning together with persistent hope is thus the overarching narrative we - Daniel and Monika - live by. Others narrate hope differently. Plato made Socrates speak of hope as of something that a person has little or no power over, something like fate (Plato's Protagoras). Aesop depicted hope as the swallow in his fables, the bird bringing spring but also, possibly, dying in the process, especially if it comes too early. But it speaks the truth, that spring is about to come, even if "one swallow does not make a summer" indeed. And then there is, of course, Pandora. The first woman received a jar which she was told not to open. Of course, she opened it, and out came all the miseries of the world. She tried to shut the jar but it was too late. The only thing left in it was - Hope. Blessing - or misfortune? There is no easy answer to this question. We suggest that it is, indeed, both, at the same time. At least that is what "our" hope - mourning and obstinacy - looks like. But it is also beautiful, because it is, at the very bottom, about devotion to something that matters, to life itself.

The narratives told by the contributors to this volume come in many shapes and colors. They are grounded in the contributors' different empirical and theoretical experiences, and guided by different philosophical, political, scientific and aesthetical underpinnings. As a consequence, many different notions of hope come to life in the following pages, as well as many different approaches to coping with the interregnum. This in turn 
is a reflection of our open call for contributions, in which we welcomed narrative explorations into the future on themes such as "alternative organizations for social inclusion and ecological blossoming," "compassion and organizing with the other," "meaningful work and workplaces" and "activists, social entrepreneurs and idealists."

The answer to our call was overwhelming, and - after having conducted a double blind review process ${ }^{1}$ - we are proud to present 18 chapters that in different ways explore hope. The chapters have been arranged in two thematic sections based on our observation that the different chapters in varying degrees are exploring utopian hope in terms of "why," "what," "where" and "how." One group of authors follow philosophical and theoretical paths addressing "why" and "what" in order to rethink hope and outline an alternative future, whereas another group of authors seek empirical and/or imaginative inspiration in order to chisel a way (or a method) out of the interregnum, stressing "where" to look for guidance and "how" to go into the future.

The distinction between these two groups is of course not strict or mutually exclusive. Both within and between these two broadly defined groups there are overlaps, nuances and contradictions that speak against our thematic structure. We do however hope that the imposed structure could serve as a meaningful road map for all those interested in continuing the conversation initiated by thinkers such as Bauman (2017a) and Streeck (2016). There might be no grand narrative on organizing hope, yet the chapters in this book, taken together, send a strong message: Organizing hope to overcome the interregnum is a complex assemblage of emic and etic inspirations fueled by inter alia new empirical vistas, metaphorical thinking, social imagination and anarchistic approaches.

The prologue preceding this introduction is a poem by Christina Ciupke and Anke Strauss invoking such metaphorical thinking and directing attention towards the different notions and streams that come after.

First out in Part One is a short reflection by Karl E. Weick (Chapter 1, "Hopeful organizing in the crucible of the interregnum"), pondering the possible workings of hope in a macro interregnum and its implications for organizing, as something unfolding.

Then, in Chapter 2, "Alternative futures: 'Hope is a thing with feathers," providing philosophical and theoretical inspirations for the future, Martin Parker seeks to rewrite critical theory and critical management studies by endowing "critical" with less cynical connotations in relation to hope. Critical diagnosis and accounts of organizations and management are not enough, Parker argues; they are only the first step in a dialectic towards the envisioning of a better future to come. Without such envisioning, critical 
theorizing is not only without any (real) consequences but also intrinsically "boring" - in the sense of conservatively reproducing more of the same, i.e. exactly those things in life that deserve to be criticized. "We should be suspicious of utopia, but enthusiastic utopians," Parker concludes.

In Chapter 3, "The utopian quest for an alternative," Roland Paulsen picks up Parker's dialectical thread of thought and wonders if it is really possible to come up with an empirically grounded (and workable) alternative to the dominant modes of production and consumption. An array of different alternatives could indeed be envisioned, from Ruth Levitas via Fredric Jameson to Erik Olin Wright, but they all reveal a troublesome paradox: The more the alternatives are turned into realpolitik, the more they are inverted under the influence of bleak There is no alternative! rhetoric - and/or by their unintended consequences. The utopian endeavor, argues Paulsen, is therefore something other than a project of (merely) opposition: "It is a challenging quest, an appeal to hope, weighted by an impossible burden of proof."

In contrast to Paulsen's conceptualization of utopia as a never-ending quest for something that might never come into existence, John Vaughan seems to have found what he has been searching for: an intellectual (dis)-position that might enable business school teachers and researchers to regain control over their thinking and actions. In Chapter 4, "Epimethean hope or Promethean expectation? The role of organisational behaviour," Vaughan chisels out this (dis)position in terms of five interrelated themes or elements: a Baumanesque critique of neoliberalism, critical thinking according to John Dewey, ideographic methodology, a progressive understanding of organizational behavior, and multi-cultural group learning. Taken together, these elements represent "a celebration of diversity and humanness," and provide fertile soil for democratic "gardening" projects, according to Vaughan.

John G. McClellan is also into democratic "gardening," although of a slightly different kind. In Chapter 5, "Transforming work into 'play": Genuine conversations as hope for meaningful organizational change," he invites the reader to partake in transforming contemporary work life, from discursive practices of self-subordination and self-alienation to selfawareness and engagement. The inspiration for such an emancipatory and hopeful transformation comes from Hans-Georg Gadamer and his notion of genuine conversation in which the "otherness of the other" is embraced in a playful manner. By opening up conversations on "subject matters" such as work-related problems, fears, feelings of emptiness, and anxieties, not only does a hopeful horizon of otherwise hidden alternatives come into existence, argues McClellan, but also mutual appreciation and meaningful collaborations. 
The democratic aspects of contemporary work and business life are also the center of attention in Chapter 6, "Hope in business organizing for societal progress: Three narratives." Here Stewart Clegg, Ace Volkmann Simpson, Miguel Pina e Cunha and Arménio Rego explore capitalist organizations and their role of providing betterment for society (or not). Their discussion is organized in terms of three narratives. The ethical narrative addresses the philosophical question of value, "What ought to be?"; the empirical narrative puts scientific focus upon the question of "What is?"; whereas the prudential narrative evolves around the political issue of "What can be?" The authors show how these three narratives have developed through history, and how they have ended up in providing contradictory answers to the posed questions. Despite the different descriptions of - and prescriptions for - corporate capitalism, the authors see hope in a nuanced and non-authoritarian understanding of business activities; and they see hope in societal and organizational democracy. Capitalist organizations may act well or badly depending on the strategic choices that they have made, but it is the responsibility of democratic governments to safeguard the public and the public good, the argument runs.

Issues of democracy and responsibility are also at stake in Wendelin Küpers's "Post-Pandoran hope for moving wisely beyond the neoPromethean Anthropocene" (Chapter 7), which closes Part One, "Philosophical and theoretical inspirations." One could, however, argue that these issues are given even greater importance, as Küpers addresses the Anthropocene and its devastating consequences on our geo-bio-social becomings. Beyond the dystopic narratives of the Anthropocene, however, there is hope, Küpers argues, but it requires a turn to practical wisdom, "a form of enacted moral excellence to create flourishing and happiness." To inculcate this turn, Küpers interprets the Anthropocene in relation to the mythical stories of Prometheus and Pandora's box, and ends up envisioning a post-anthropocentric age, devoid of Promethean hubris and fueled by the release of Pandoran hope. Küpers calls this age the "eco- or $z o \ddot{e}$-cene," the era of "meanings of life in an ecological sense."

In Part Two, "Empirical and imaginative inspirations," Richard Longman follows suit with a study on alternative organizing, "Hope-full purpose': Time, oblivion, and the strange attractors of Pandora's box" (Chapter 8). The explicit objective, for Longman, is to unite Pandoran hope with purpose because, as he argues, "retrieving the hope that is lodged at the bottom of Pandora's box must be a purposeful act." If so, then it "requires us to become agents of change, living out relationships and practices that remedy our present shortcomings and characterize a better future," as Longman puts it. The empirical location of investigation is Medium, an online site of social journalism, and, based on his readings 
of the case, Longman presents a "portmanteau construction" in terms of "hope-full purpose" - a construction that he hopes offers an organizational alternative to "short-term gain and individual egoism."

Similarly to Longman, George Cairns writes against the prevalent self-interest and discriminatory powers of contemporary forms of organization, looking for self-organizing communities working for the common good. His remedy to the situation in Chapter 9, "Against organization - farewell to hope?," is however different. The betterment of society, he argues, requires the de(con)struction of "hope" and "organization" as we currently know the two concepts, and the simultaneous rejection of how they currently are being used and appropriated by elite actors. Cairns sees potential in both Feyerabend's intellectual approach and Guillet de Monthoux's ideas on anarchism, but he is also empirically inspired by three very different community initiatives: a housing co-op, community facility services, and a parallel currency. "The key aim," Cairns concludes, "must be to find a minimum common ground within different world-views that will provide hope for a better shared future while enabling true diversity and individuality at the local level."

Also for Anna Góral, the local community is put in focus, as it is believed to form the basis for alternative organizations striving for resilience, sustainability and social inclusion. In Chapter 10, "Idealists and dreamers: Struggling for more resilient communities via alternative organisations," Góral tries to find out what makes people tick in such organizations, despite the many hardships they often encounter. She finds an answer to her query by studying three different empirical cases (a community center, a support agency for rural development, and an interest organization for disabled people), and she arrives at the conclusion that resilience goes hand in hand with people who firmly believe that their visions and engagement will have real social impact. They are idealists and dreamers, activists and altruists - and, as such, they function as the "axis mundi" of their local communities.

In Chapter 11, "Cadriste (R)Evolution," Markus Kallifatides shifts focus from local communities producing social good to nation-state democracies grappling with social injustices and environmental destruction. For these democracies to be successful, the capitalistic formula of "money, commodity, more money" must, according to Kallifatides, be replaced by an alternative formula in which "money must be invested in something other than commodities, and the 'return on investment' must be something other than more money." Kallifatides calls thus for a (r)evolution, and the inspiration for this he finds in the institutional particularities of Sweden and the so-called "Swedish model." Daydreaming away, Kallifatides conjures up a provisional utopia of institutional investments, and a class alliance of the 
urban middle classes and wage laborers. This cadre becomes a reformist avant-garde that enables a shift in the power balance from capital to labor - "and from those now alive to those not yet born."

Tali Padan is also occupied by the necessity of change in order to counteract the devastating consequences of crumbling institutions. Her focus however is on democratic citizenship education, i.e. the development of political, social and moral literacy, and she queries the type of learning processes that could make young people develop such skills, as well as prepare them to bridge the tensions between on the one hand the individual and the collective, and diversity and unity on the other. In Chapter 12, "The hope of discomfort: Using democratic citizenship education for transformative learning," Padan turns to Mezirow's concept of "transformative learning" for inspiration, and she reports from her own experiences in working with the Betzavta method. Centered around a "discomforting dilemma," this method encourages the participants not only to reflect upon their selves and their experiences but also to confront the very assumptions they make about the world and others - even if it hurts - because it is in the experienced discomfort, Padan argues, that hope resides; it makes the participants more open and emotionally able to change.

A different pathway to emancipation that might make it possible to move beyond the present-day interregnum is offered by Daniel Ericsson in Chapter 13, "Technologies of the commune: A bridge over troubled water?" Ericsson's point of departure is what Foucault called "technologies of the self," epistemological truth games that individuals use on themselves to attain a desired state of being, such as the sacrificing of oneself by subordination. From the perspective of capitalism's technologies of the self, Ericsson advocates an alternative epistemology that is "neither selfcentred nor directed towards self-discipline," and sets out to narrate this in terms of "technology of the commune." The protagonist of his narrative is Toffler's utopian "prosumer," and the plot twists into the music industry and the phenomenon of "house concerts." Listening to the experiences of "prosumers" enacting such "house concerts," Ericsson chisels out the sense moral: the music industry is reconfiguring into a collective knowledgemaking project that seems to free the actors from "(at least some of) the yokes of capitalism."

The field of culture is also the empirical vista for Agata Morgan. In Chapter 14, "'Dad, Do Not Cry': Imagination and creativity on their own terms in inclusive cities and communities," she challenges the concept of creativity, especially as it has been used by Richard Florida in his works on the "creative class," and argues for a more inclusive conceptualization of creativity. For inspiration on how to create a new narrative on creativity, in which creativity is enacted for a greater good rather than only serving a 
chosen elite, Morgan turns to visual artist Łukasz Surowiec and his mural paintings. In Surowiec's artwork Morgan finds a powerful story of social change that "restores our hope in better, more inclusive cities and communities," and through which otherwise silenced voices are being heard.

Marta Połeć also turns to the field of culture as she focuses upon a somewhat marginalized urban phenomenon: street performances. In Chapter 15, "Street performances in hope for the future of the urban sphere: Human interaction, self-realization and emotive enactment," she reports on an ethnographic study carried out in several Polish cities where she has followed tens of performers closely and attentively. She argues that street performances can be seen as inspiring and hopeful in many ways. Firstly, street performances inform us about what it means to be human, carrying values such as trust, cooperation and kindness, thus contributing to a humanistic atmosphere of public domains. Secondly, street performances express the right to live one's life regardless of any social and normative expectations. And, thirdly, street performances represent emotional enactment. If we could live as we learn at the street shows, Połeć concludes, our lives would definitely be "more friendly, interactive, mindful and trustful."

If street performances embrace the richness of life, then linearity kills it. Linearity is a "morbid activity," write Michał Izak and Monika Kostera in Chapter 16, "There is hope in organizing: Dialogic imagination against linearity," because it aspires "to cleanse the world of all ambivalence ... everything that is poetic and baroque." Izak and Kostera therefore set out to replace linearity and linear thinking with metaphorical thinking and dialogic imagination as an inspiration for alternative organizing into the future. Backed by extensive ethnographic field work carried out in a variety of organizations, their arguments unfold in the form of a compelling tale: where room is made for imagination, not only new organizational understandings and directions emerge but also meaningful interactions. Imagination releases and encompasses organizational dynamics otherwise suppressed, and allows otherwise unseen and silent actors to partake in organizational sensemaking. "And therein lies our hope," Izak and Kostera conclude, "as a desire motivated by the forlorn state of much of the organizational world as it is."

In Chapter 17, "Good labour: Affirmative work awareness and hope," Małgorzata Ćwikła brings "work" back into the discussion about the meaning and richness of life. Work, as it has been predominantly problematized within contemporary research, is most often associated with things like exploitation, inequalities, blurred boundaries and so on, but Ćwikła is eager to change this. By approaching work with an affirmative attitude, she therefore turns the research agenda upside down through simply asking people to describe what they find good about their jobs. 
Her study reveals that the answers to this question could be categorized into elements in organizations such as "interpersonal relations," "range of duties" and "personal attitude." For Ćwikła, these elements indicate what might be missing in contemporary work life, and probably should form the basis for organizational projections into the future.

Aneta Milczarczyk also has an interest in the good aspects of life, but her interest is directed towards people who want to make the world a better place to live in for others - and who actually take actions to make their dreams and visions come true. In Chapter 18, "Actors of goodness and hope in action," Milczarczyk presents a case study of such people working at the Southend Credit Union, an initiative taken to tackle an experienced injustice in the local community, and geared at helping marginalized people to straighten out their lives by straightening out their finances. What comes out of Milczarczyk's interpretation is a kind of self-fulfilling prophecy of hope: The actors at Southend Credit Union are led by their hope of making things better, and their actions bring hope into the local community - which in turn fosters the notion of collective hope. All in all, argues Milczarczyk, hope is a stimulus for social change.

Pondering the mystery of writing, rock musician and poet Patti Smith (2017) asks herself why she is doing it. Her answer to the question is revealed in the book's title, Devotion. It is neither an optimistic mindset nor determination that defines it, but something quite different. In the author's own words:

Things are slow moving. There is a pencil stub in my pocket.

What is the task? To compose a work that communicates on several levels, as in a parable, devoid of the stain of cleverness.

What is the dream? To write something fine, that would be better than I am, and that would justify my trials and indiscretions. To offer proof, through a scramble of words, that God exists.

Why do I write? My finger, as a stylus, traces the question in the blank air. A familiar riddle posed since youth, withdrawing from play, comrades and the valley of love, girded with words, a beat outside.

Why do we write? A chorus erupts.

Because we cannot simply live. (Smith, 2017, p. 93)

What is writing for our contributors in this volume? It is now for you to find out. 


\section{NOTE}

1. The editors would like to express the deepest gratitude to all of our colleagues who took their time to review one or several chapters: Sylwia Ciuk, Stewart Clegg, Mathilda Dahl, Krzystof Durczak, Daniel Ericsson, Malin Gawell, Anna Góral, Jenny Helin, Michal Izak, Tommy Jensen, Kenneth Mølbjerg Jørgensen, Markus Kallifatides, Monika Kostera, Wendelin Küpers, Richard Longman, Tomasz Ludwicki, Henrietta Nilsson, Daniel Nyberg, Tomasz Ochinowski, Tali Padan, Alexia Panayiotou, Roland Paulsen, Marta Połeć, Anette Risberg, Joanna Srednicka, Anke Strauß and Marta SzelugaRomanska. Without your effort, the book would simply not have come into existence. 